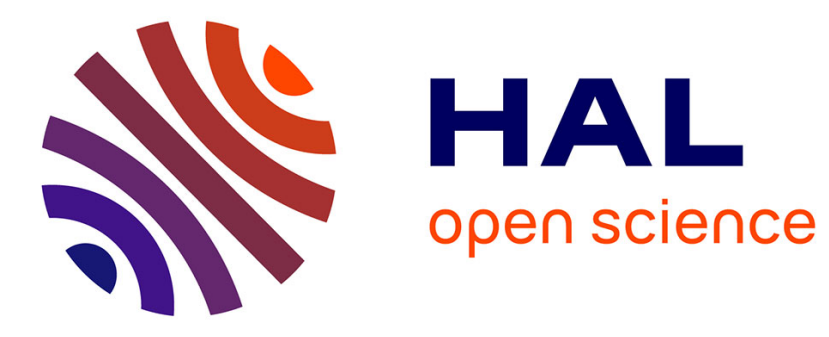

\title{
Structural changes induced by heavy ion irradiation in titanium silicon carbide
}

Jean-Christophe Nappé, Isabelle Monnet, Philippe Grosseau, F. Audubert, Bernard Guilhot, Michel Beauvy, Mourad Benabdesselam, Lionel Thomé

\section{To cite this version:}

Jean-Christophe Nappé, Isabelle Monnet, Philippe Grosseau, F. Audubert, Bernard Guilhot, et al.. Structural changes induced by heavy ion irradiation in titanium silicon carbide. Journal of Nuclear Materials, 2011, 409 (1), pp.53-61. 10.1016/j.jnucmat.2010.12.235 . hal-00558236

\section{HAL Id: hal-00558236 https://hal.science/hal-00558236}

Submitted on 21 Jan 2011

HAL is a multi-disciplinary open access archive for the deposit and dissemination of scientific research documents, whether they are published or not. The documents may come from teaching and research institutions in France or abroad, or from public or private research centers.
L'archive ouverte pluridisciplinaire HAL, est destinée au dépôt et à la diffusion de documents scientifiques de niveau recherche, publiés ou non, émanant des établissements d'enseignement et de recherche français ou étrangers, des laboratoires publics ou privés. 


\title{
Structural changes induced by heavy ion irradiation in titanium silicon carbide
}

\section{Authors}

J.C. Nappée ${ }^{\mathrm{a},}{ }^{\dagger}$, I. Monnet ${ }^{\mathrm{b}}$, Ph. Grosseau ${ }^{\mathrm{a}}$, F. Audubert ${ }^{\mathrm{c}}$, B. Guilhot ${ }^{\mathrm{d}}$, M. Beauvy ${ }^{\mathrm{b}}$, M. Benabdesselame ${ }^{\mathrm{e}}$, L. Thoméf

a École Nationale Supérieure des Mines, SPIN/PMMC, LPMG UMR CNRS 5148, 158 cours Fauriel, 42023 Saint-

Étienne cedex 2, France

${ }^{\mathrm{b}}$ CIMAP, CEA-CNRS-ENSICAEN-Université de Caen Basse Normandie, Bd Henri Becquerel, BP 5133, F-14070 Caen cedex 5, France

${ }^{\mathrm{c}}$ CEA, DEN, DEC/SPUA/LTEC, Cadarache, 13108 St Paul lez Durance, France

d École Nationale Supérieure des Mines, CIS/B2M, 158 cours Fauriel, 42023 Saint-Étienne cedex 2, France

${ }^{\text {e }}$ Université de Nice - Sophia Antipolis, LPMC UMR CNRS 6622, Parc Valrose, 06108 Nice cedex 2, France

${ }^{\mathrm{f}}$ Centre de Spectrométrie Nucléaire et de Spectrométrie de Masse, CNRS-IN2P3-Université Paris Sud, UMR 8609, Bât. 108, 91405 Orsay, France

\begin{abstract}
Carbide-type ceramics, which have remarkable thermomechanical properties, are sensed to manufacture the fuel cladding of Generation IV reactors that should work at high temperature. The MAX phases, and more particularly titanium silicon carbide, are distinguished from other materials by their ability to have some plasticity, even at room temperature. For this study, polycrystalline $\mathrm{Ti}_{3} \mathrm{SiC}_{2}$ was irradiated with ions of different energies, which allow to discriminate the effect of both electronic and nuclear interactions. After characterization by low-incidence $\mathrm{X}$-ray diffraction and cross-sectional transmission electron microscopy, it appears that $\mathrm{Ti}_{3} \mathrm{SiC}_{2}$ is not sensitive to electronic excitations while nuclear shocks damage its structure. The results show the creation of many defects and disorder in the structure, an expansion of the hexagonal close-packed lattice along the $\mathrm{c}$ axis, and an increase in the microstrain yield.
\end{abstract}

Keywords: $\mathrm{Ti}_{3} \mathrm{SiC}_{2}$, ion irradiation, nuclear and electronic interactions, low-incidence X-ray diffraction, cross-sectional transmission electron microscopy

PACS: 81.05.Je, 61.80.-x, 61.80.Lj, 25.75.Ag, 34.50.Bw, 28.41.Bm, 61.05.C-, 68.37.Og

\section{Introduction}

The Gas Fast Reactor (GFR), one of the six systems considered by the Generation IV International Forum (GIF), is designed for nominal working at both high temperature and high helium pressure [1]. These working conditions led to the selection of non-oxide ceramics as cladding material for the fuel. Therefore, researches aiming at understanding the behavior under irradiation of carbides were carried out in recent years [2-7].

Among the studied materials, titanium silicon carbide can be distinguished by its propensity to combine the properties of ceramics with those generally attributed to metals [8-14]. Indeed, like most of the MAX phases, $\mathrm{Ti}_{3} \mathrm{SiC}_{2}$ is stiff (Young's modulus of $352 \mathrm{GPa}[15,16]$ ), tough (toughness of $9 \mathrm{MPa} \mathrm{m}^{1 / 2}[16,17]$ ) and soft (hardness of $6 \mathrm{GPa}$ ), both thermal and electrical conductor $\left(37 \mathrm{~W} \mathrm{~m}^{-1} \mathrm{~K}^{-1}[18]\right.$ and $4.5 \times 10^{6} \Omega^{-1} \mathrm{~m}^{-1}[19,20]$, respectively), and resistant to thermal shocks $[15,21,22]$. In particular, the plasticity of $\mathrm{Ti}_{3} \mathrm{SiC}_{2}$ at room temperature may be explained by its nanolamellar structure, which confers to $\mathrm{Ti}_{3} \mathrm{SiC}_{2}$ material a propensity to delaminate under the effect of mechanical stress [22-24]. However, if the behavior of this material has already been studied under various conditions more or less extreme [20,21,25-28], except few articles related to $\mathrm{Ti}_{3} \mathrm{SiC}_{2}$ that were recently published [29-32], and others related to $\mathrm{Ti}_{3}(\mathrm{Si}, \mathrm{Al}) \mathrm{C}_{2}$ [33-36], no study has been conducted on the irradiation behavior of $\mathrm{Ti}_{3} \mathrm{SiC}_{2}$.

† $\quad$ Corresponding author. Tel.: +33 477420 213; fax: +33 477499694 .

E-mail address: jc.nappe@yahoo.fr (JC. Nappé). 
Therefore, in this study, the damage of $\mathrm{Ti}_{3} \mathrm{SiC}_{2}$ under irradiation is analyzed from the structural point of view, using both low-incidence X-ray diffraction and cross-sectional transmission electron microscopy.

\section{Experimental}

\subsection{Material}

The studied material is a polycrystalline $\mathrm{Ti}_{3} \mathrm{SiC}_{2}$ provided by 3-ONE-2 (Vorhees, NJ, USA). Like most $\mathrm{Ti}_{3} \mathrm{SiC}_{2}$ bulk samples, our specimens contain impurities: about $19 \%$ of $\mathrm{TiC}_{0.92}$ and $7 \%$ of $\mathrm{TiSi}_{2}$ (estimation by X-ray diffraction). The samples provided in the form of plates are cut into parallelepipeds of about $10 \times 5 \times 5 \mathrm{~mm}^{3}$, and one face is polished with diamond paste with a particle size down to 1 micron. Finally, they are irradiated on the polished face.

\subsection{Irradiations}

The neutron irradiations that occur in the reactor have been simulated with ions to allow characterization of the irradiated samples without special precautions. Table 1 summarizes the irradiations performed in this study: knowing that the GFR should work at high temperature, in addition to the effect of both the energy and the fluence, the effect of irradiation temperature was investigated.

Table 1: Irradiations performed for this study.

\begin{tabular}{|c|c|c|c|}
\hline Beamline & Ion & Temperature (K) & Fluences $\left(\mathrm{m}^{-2}\right)$ \\
\hline \multirow{3}{*}{ ARAMIS } & & 298 & $10^{16}, 10^{17}, 10^{18}, 10^{19}$ \\
\hline & $4 \mathrm{MeV} \mathrm{Au}$ & 773 & $10^{16}, 10^{17}, 10^{18}, 10^{19}$ \\
\hline & & 1623 & $10^{19}$ \\
\hline \multirow{4}{*}{ IRRSUD } & & 298 & $10^{16}, 10^{17}, 10^{18}, 10^{19}$ \\
\hline & 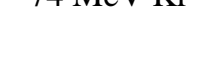 & 773 & $10^{16}, 10^{17}, 10^{18}, 10^{19}$ \\
\hline & $92 \mathrm{MeV}$ Xe & 298 & $\begin{array}{c}10^{16}, 10^{17}, 2 \times 10^{17}, 4 \times 10^{17}, 8 \times 10^{17}, 10^{18} \\
2 \times 10^{18}, 4 \times 10^{18}, 8 \times 10^{18}, 10^{19}, 1.3 \times 10^{19}\end{array}$ \\
\hline & & 573 & $10^{16}, 10^{17}, 10^{18}, 10^{19}$ \\
\hline \multirow{3}{*}{ SME } & & 298 & $10^{15}, 10^{16}, 10^{17}, 4.5 \times 10^{17}$ \\
\hline & $930 \mathrm{MeV}$ Xe & & \\
\hline & & 773 & $10^{15}, 10^{16}, 10^{17}, 4.5 \times 10^{17}$ \\
\hline
\end{tabular}

The kinetic energy of a neutron is predominantly transferred to the primary knock-on atom (PKA) of the target in an elastic collision. Following this shock, the PKA becomes a projectile and causes nuclear interactions with atoms of the target. Thus, the low-energy ions, which induce mainly nuclear shocks, are used to simulate neutron irradiations. This is the reason to carry out irradiation with $4 \mathrm{MeV}$ ions provided by the ARAMIS accelerator of CSNSM (Orsay, France).

However, as the damage induced by this irradiation is localized in a small volume (Figure 1), characterization of the irradiated area can turn out to be tricky. Therefore, irradiations with higher energy ions have been carried out on the IRRSUD beamline at GANIL (Caen, France) with $74 \mathrm{MeV} \mathrm{Kr}$ and $92 \mathrm{MeV}$ Xe ions. These irradiations generate nuclear shocks that increase with the depth (Figure 1), allowing the characterization of the damage as a function of dpa (number of "displacements per atom" of the target). 


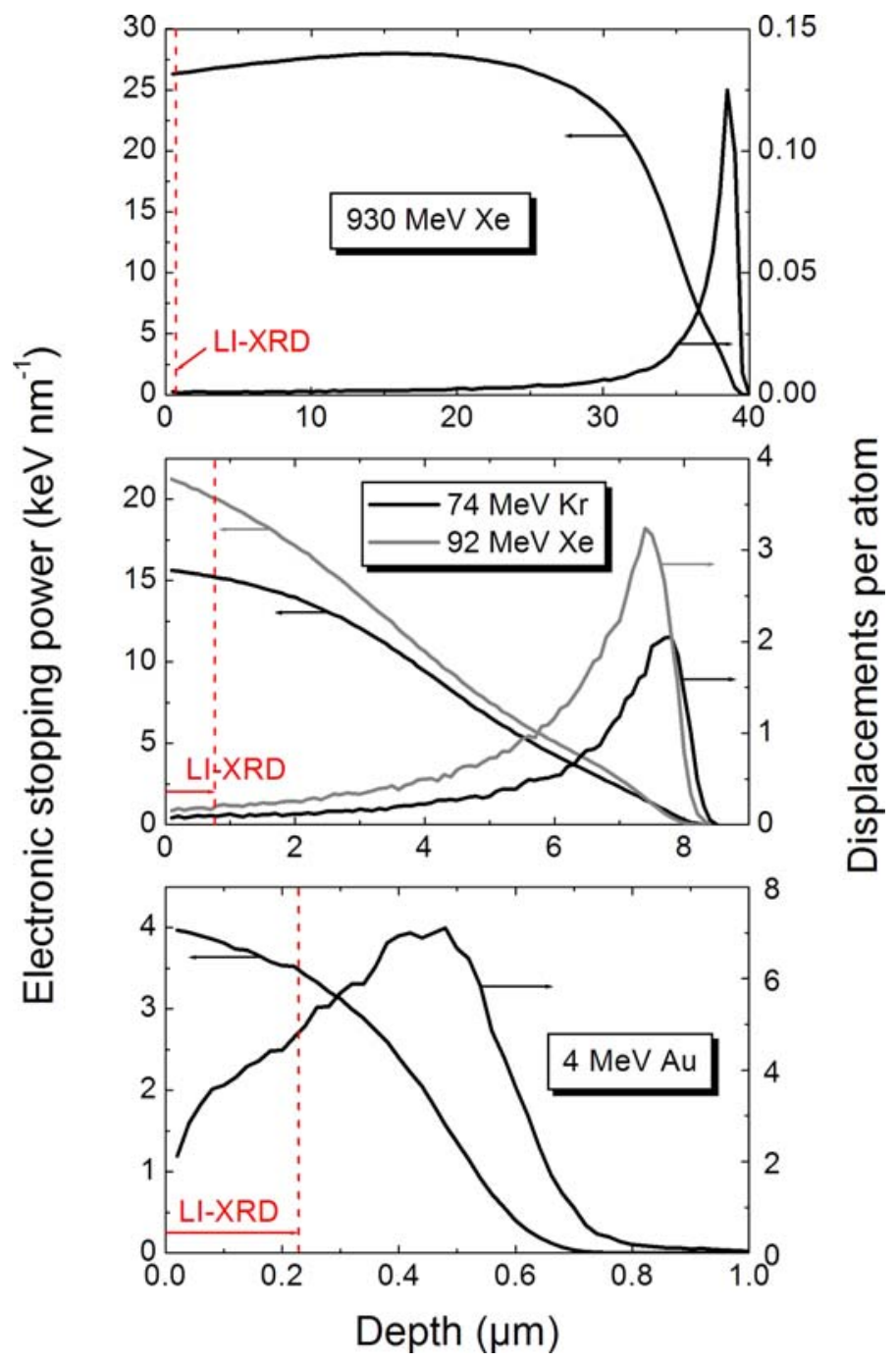

Figure 1: Electronic stopping power and number of displacements per atom induced by each irradiation as a function of the depth in $\mathrm{Ti}_{3} \mathrm{SiC}_{2}$; dpa are for the maximal fluence $\left(10^{19} \mathrm{~m}^{-2}\right.$ for $4 \mathrm{MeV} \mathrm{Au}, 74 \mathrm{MeV} \mathrm{Kr}$ and $92 \mathrm{MeV}$ Xe, $4.5 \times 10^{17} \mathrm{~m}^{-2}$ for $930 \mathrm{MeV}$ Xe). Data were determined with the TRIM-2008 code [37].

Nevertheless, at the beginning of the range, electronic interactions induced by the irradiations performed on IRRSUD are important. To discriminate the effect of both electronic and nuclear interactions, irradiations with a higher energy have been carried out on the SME beamline at GANIL with $930 \mathrm{MeV}$ Xe ions; for these irradiations, nuclear shocks can be considered as negligible along the first 30 microns (Figure 1). The fluences reached for this irradiation are lower than those of other irradiations (Table 1): this is due to the fact that the flux used for this irradiation was reduced to avoid the heating of the specimens. Anyway, in several materials sensitive to electronic interactions, it was shown that such fluences can cause significant damage [38-40].

\subsection{Characterization techniques}

The as-irradiated samples were characterized by low-incidence X-ray diffraction (LI-XRD). The diffractometer used was a Siemens D5000 equipped with copper anticathode $(0.154 \mathrm{~nm})$. The diffractograms were recorded between $5^{\circ}$ and $90^{\circ}$ in $2 \theta$ scale, under an incidence of $1^{\circ}$ for samples irradiated with $4 \mathrm{MeV}$ Au ions, and $3^{\circ}$ for other irradiations. Under these incidences, the X-ray intensity in $\mathrm{Ti}_{3} \mathrm{SiC}_{2}$ decreases by a factor of 2.72 at a depth of $230 \mathrm{~nm}$ and $760 \mathrm{~nm}$ respectively [41-43]. An aluminum-made mask was placed on the virgin part of some specimens partly irradiated.

Variations of lattice parameters were determined using the TuneCell tool of Diffractplus EVA software provided by Bruker. The measure of the microstrain yield was conducted by evaluating the broadening of the (104) peak of $\mathrm{Ti}_{3} \mathrm{SiC}_{2}$ (the most intense isolated peak), and by considering that the crystallite size is large enough not to induce broadening; this consideration is motivated by observations made by Electron Back-Scatter Diffraction (EBSD), which allowed us to highlight a crystallite size greater than $1 \mu \mathrm{m}$ [29]. 
Some samples were also observed by cross-sectional transmission electron microscopy (X-TEM) with a view to both understand the damage noted by LI-XRD and observe the defects induced by irradiation. The microscope used was a 200 kV Jeol 2010F, equipped with a field emission gun.

These techniques were also applied on an as-polished and no irradiated sample, so-called virgin sample, to highlight the differences induced by irradiation.

\section{Results}

\subsection{Disorder and defects}

Figure 2 shows diffractograms recorded on several irradiated samples, which complete a previous study [30].

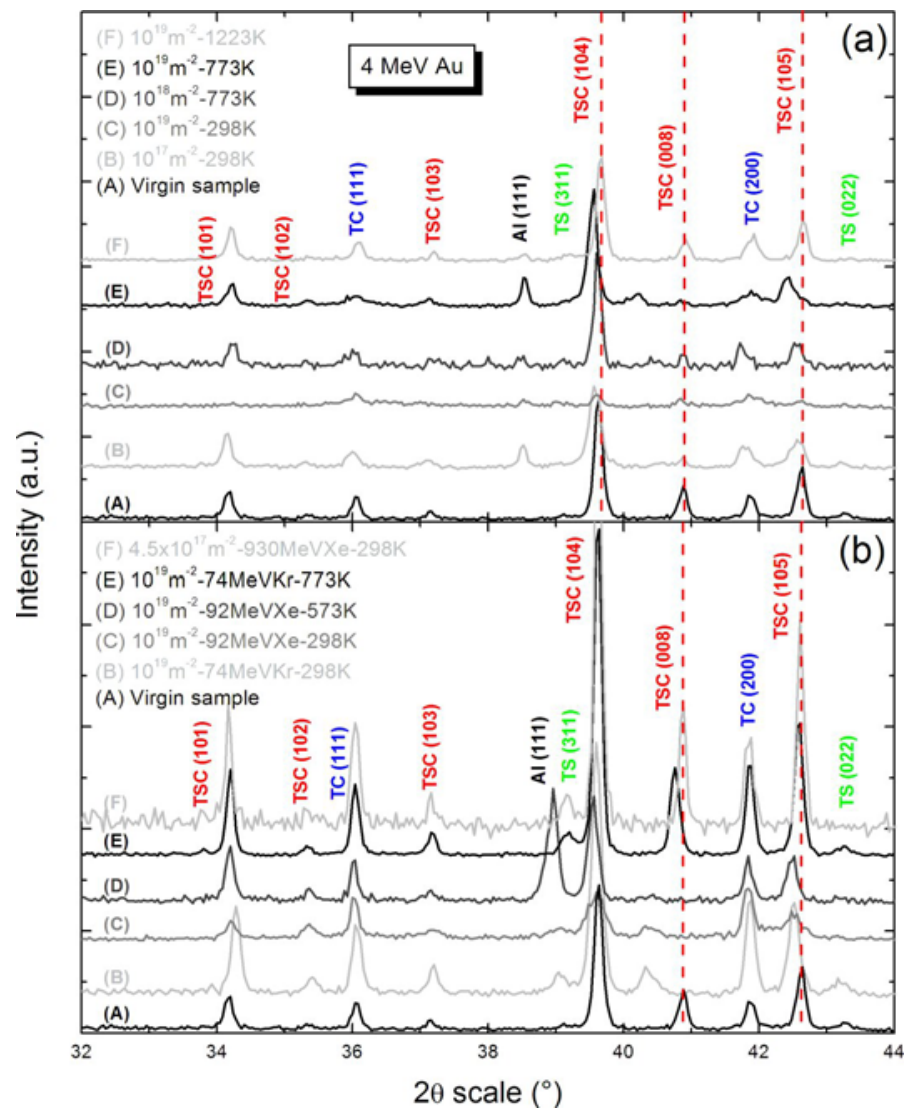

Figure 2: Diffraction pattern of samples irradiated with (a) $4 \mathrm{MeV}$ Au ions (analysis angle: $1^{\circ}$ ), and (b) high-energy ions (analysis angle: $3^{\circ}$ ); $\mathrm{Al}(111)$ peaks are due to an aluminum-made mask placed on the virgin part of partly irradiated samples.

Concerning the $4 \mathrm{MeV}$ Au ion irradiation, we have shown a significant change of the material structure at $298 \mathrm{~K}$, which was attributed to some loss of crystallinity; this phenomenon can be observed through both a decrease of the peak intensity and a rise in the baseline. By comparing these diffractograms with those obtained for specimens irradiated at $773 \mathrm{~K}$ (Figure 2a), the damage seems less important at this latter temperature, indicating a positive effect of the temperature on the material damage. This positive effect is even more noticeable for the sample irradiated at $1223 \mathrm{~K}$, the diffractogram being identical to that of the virgin sample.

Concerning the $92 \mathrm{MeV}$ Xe ion irradiation, we have also shown a significant change in the material structure at $298 \mathrm{~K}$, but less significant than for $4 \mathrm{MeV}$ Au ion irradiation. This result may also be noticed on the diffractogram obtained from the specimen irradiated at $298 \mathrm{~K}$ with $74 \mathrm{MeV} \mathrm{Kr}$ ions to $10^{19} \mathrm{~m}^{-2}$ (Figure 2b). It is noteworthy that, like for $4 \mathrm{MeV} \mathrm{Au}$ ion irradiation, the higher the irradiation temperature, the lower the damage induced by irradiations with $74 \mathrm{MeV}$ Kr or $92 \mathrm{MeV}$ Xe ions. 
Another interesting result is that, for $930 \mathrm{MeV}$ Xe ion irradiation, no change in the diffractograms is noticeable (Figure 2b). For materials sensitive to electronic interactions, the fluences reached in this study may lead to a whole amorphization of the material [38-40]; thus, it seems that electronic excitations are not harmful to $\mathrm{Ti}_{3} \mathrm{SiC}_{2}$.

The results obtained by LI-XRD are in agreement with the observations made by X-TEM (Figure 3). Before irradiation, $\mathrm{Ti}_{3} \mathrm{SiC}_{2}$ does not contain any defects (see the virgin area of Figure 3a), and its nanolamellar structure is noticeable on both the micrographs and the diffraction patterns ( 3 spots of low intensity between 2 more intense ones) (Figure 3b).

After irradiation, no defect has been observed on samples irradiated with $930 \mathrm{MeV} \mathrm{Xe}$ ions, confirming the insensitivity of $\mathrm{Ti}_{3} \mathrm{SiC}_{2}$ to electronic excitations. On the contrary, many defects appearing as black dots (see irradiated area of Figure 3a) are present in other samples. These black dots are too small to be identified by TEM; as evocated by Le Flem et al. they could be clusters of Frenkel pairs or dislocation loops [33]. The concentration of these black dots increases with depth for samples irradiated on the IRRSUD beamline, confirming that they are induced by the nuclear shocks.

Moreover, when the number of dpa increases, the nanolamellar structure of $\mathrm{Ti}_{3} \mathrm{SiC}_{2}$ disappears (Figure 3c and d); this may be observed on the micrographs as well as on the diffraction patterns. However, the close-packed stacking of the hexagonal structure is still notable; hence it seems that the material does not become amorphous. We could not determine the cause of the disappearance of the nanolamellar structure. But considering the crystal structure of $\mathrm{Ti}_{3} \mathrm{SiC}_{2}[19,44,45]$, it seems that the most likely hypothesis to explain this damage of nanolamellar structure would be the substitution of silicon atoms by titanium ones (and/or vice versa) due to nuclear shocks, inducing the creation of defects like $\mathrm{Ti}_{\mathrm{Si}}$ (and/or $\mathrm{Si}_{\mathrm{Ti}}$ ); this hypothesis was also propounded by Le Flem et al., who noted similar results in their material [33].

The increase of the temperature reduces the concentration of black dots as well as the damage of the nanolamellar structure (Figure 3e). 

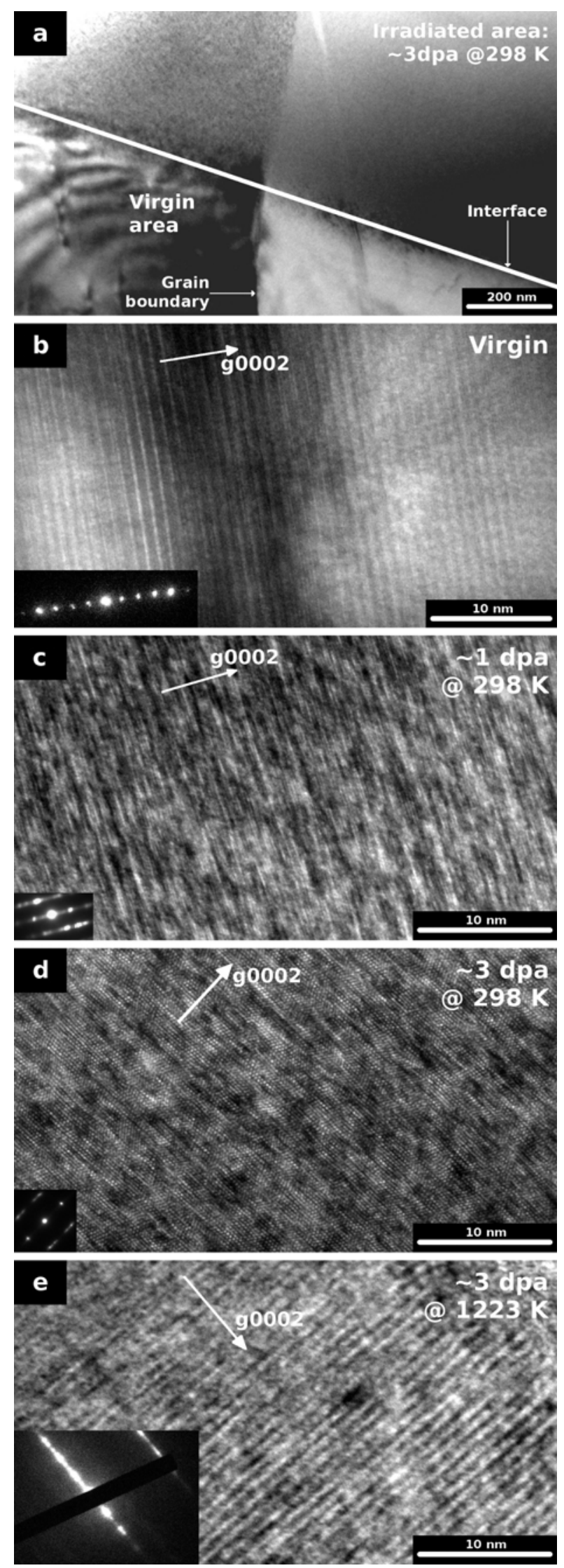

Figure 3: (a) X-TEM picture of an overview of the interface between the irradiated and the virgin areas of the sample irradiated at $298 \mathrm{~K}$ with $4 \mathrm{MeV}$ Au ions to $10^{19} \mathrm{~m}^{-2}$. (b-e) High resolution X-TEM pictures: (b) virgin sample, (c) and (d) sample irradiated at $298 \mathrm{~K}$ with $92 \mathrm{MeV}$ Xe ions to $10^{19} \mathrm{~m}^{-2}$, obtained at the beginning and at the end of the ion range respectively, and (e) sample irradiated at $1223 \mathrm{~K}$ with $4 \mathrm{MeV}$ Au ions to $10^{19} \mathrm{~m}^{-2}$. Vector noted g0002 is perpendicular to $<0002>$ planes. 


\subsection{Change in lattice parameters}

Previously, we showed that irradiation with $92 \mathrm{MeV}$ Xe ions induces both an expansion of the hexagonal lattice of $\mathrm{Ti}_{3} \mathrm{SiC}_{2}$ along the c axis, and a contraction along the a axis [30]. These variations seemed to occur without change in the unit cell volume. In this study, additional measurements were performed (Figure 4); measurements on specimens irradiated with $930 \mathrm{MeV}$ Xe ions are not shown because no change in lattice parameters could be highlighted.
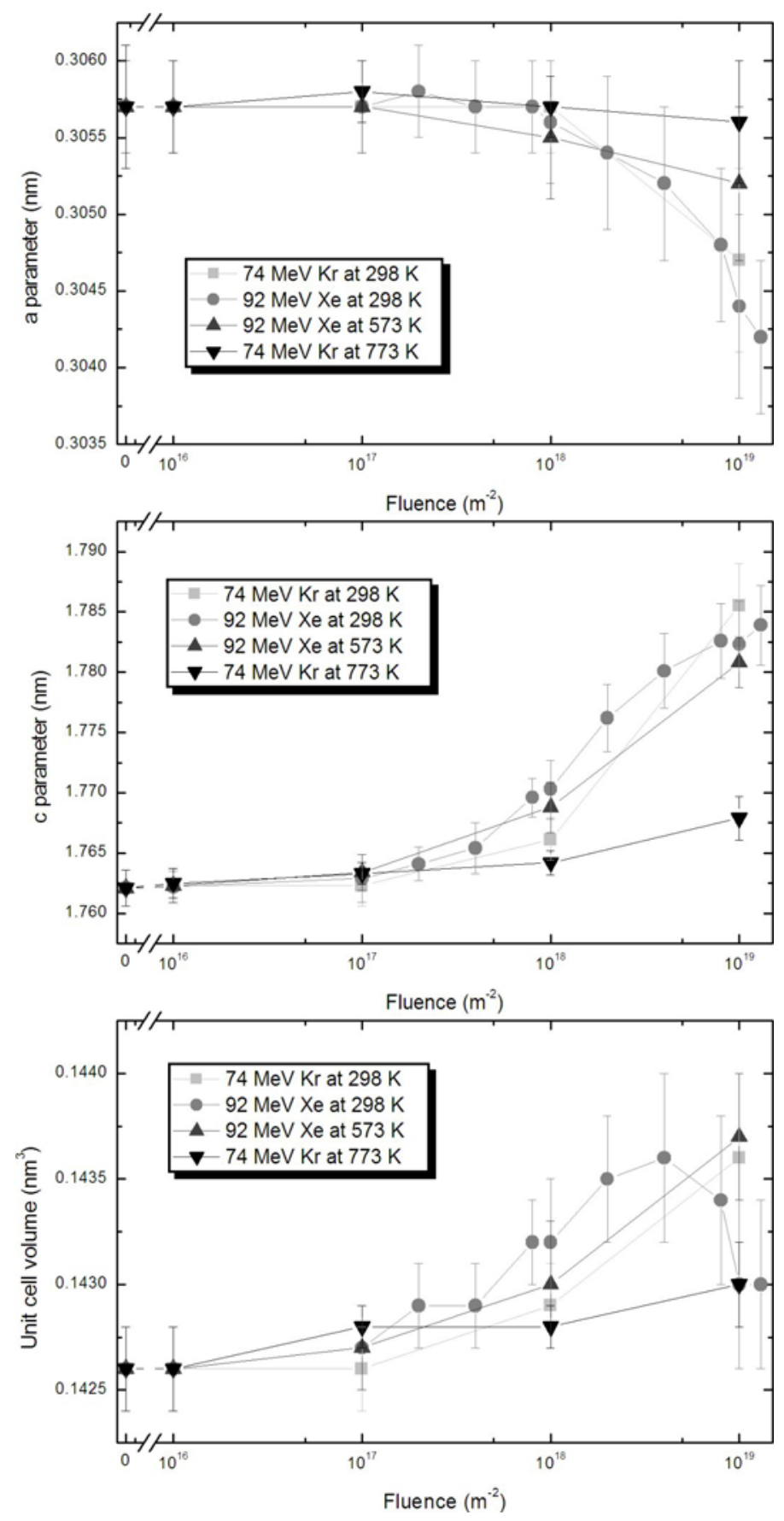

Figure 4: Change in lattice parameters as a function of ion fluence for irradiations performed on IRRSUD.

For the $92 \mathrm{MeV}$ Xe irradiations at $298 \mathrm{~K}$, the contraction along the a axis would begin from about $10^{18} \mathrm{~m}^{-2}$, while the expansion along c would start from about 2 to $4 \times 10^{17} \mathrm{~m}^{-2}$; the variations seem to be the same for irradiations with $74 \mathrm{MeV} \mathrm{Kr}$ ions. Contrary to what had previously been concluded with data on samples irradiated with $92 \mathrm{MeV}$ Xe ions to $10^{18}$ and $10^{19} \mathrm{~m}^{-2}$ [30], these changes induce an increase of the unit cell volume that reaches a maximum for irradiation with $92 \mathrm{MeV}$ Xe ions, and not for irradiation with $74 \mathrm{MeV} \mathrm{Kr}$ ions. This difference will be discussed later on. 
Concerning the effect of temperature, it seems that the highest temperature, the lowest changes in both a and c parameters, confirming the beneficial effect of temperature to reduce irradiation damage.

Finally, on the diffractograms of samples irradiated with $4 \mathrm{MeV} \mathrm{Au}$ ions (Figure 2), a peak is noticeable between the (104) and (008) peaks of $\mathrm{Ti}_{3} \mathrm{SiC}_{2}$. Moreover, by paying attention to both (104) and (105) peaks of $\mathrm{Ti}_{3} \mathrm{SiC}_{2}$, they appear to be deformed compared with that of the virgin sample, and shifted to lower $2 \theta$. After comparing both of these phenomena with the diffractograms of specimens irradiated on the IRRSUD beamline, especially with the one irradiated at $298 \mathrm{~K}$ with $74 \mathrm{MeV} \mathrm{Kr}$ ions to $10^{19} \mathrm{~m}^{-2}$ (Figure 2), it appears that despite the low incidence angle $\left(1^{\circ}\right)$ the diffractograms of samples irradiated with $4 \mathrm{MeV}$ Au ions present a contribution of both the irradiated area and the virgin one located at about 1 micron (Figure 1). Therefore, these irradiations also induce a variation of lattice parameters, and then it seems that the change in lattice parameters is due to nuclear shocks. Unfortunately, due to the degradation of the crystallinity of the samples with the $4 \mathrm{MeV}$ Au ion fluence, only three diffraction patterns (of samples irradiated at $298 \mathrm{~K}$ to $10^{17} \mathrm{~m}^{-2}$, and at $773 \mathrm{~K}$ to both $10^{18}$ and $10^{19} \mathrm{~m}^{-2}$, see Figure 2) allow one to notice a peak shift: it is hence not possible to present the evolution of lattice parameters as a function of the fluence or irradiation temperature. Nevertheless, this result will enrich the discussion.

\subsection{Change in microstrain yield}

Through X-TEM observations of irradiated samples, the crystallite size does not seem to decrease. That is why, in a first approximation, we consider that the broadening of the $\mathrm{Ti}_{3} \mathrm{SiC}_{2}$ diffraction peaks is only due to an increase of the microstrain yield (see section 2.3.); from a Williamson and Hall analysis, Liu et al. have also noticed that the peak broadening induced by identical irradiations, but on $\mathrm{Ti}_{3} \mathrm{Si}_{0.90} \mathrm{Al}_{0.10} \mathrm{C}_{2}$, is only due to an increase of the microstrain yield [34]. Moreover, since the diffraction patterns of specimens irradiated with $4 \mathrm{MeV} \mathrm{Au}$ ions partly consist of the virgin material located at the end of the irradiated thickness, measurements of the broadening of the (104) peak does not allow to obtain information arising from the irradiated area alone. Therefore, no measurement has been performed for these irradiations.

The materials irradiated on the IRRSUD beamline at $298 \mathrm{~K}$ show an increase of the microstrain yield as a function of the fluence (Figure 5). As for the lattice parameter changes, irradiation with $92 \mathrm{MeV} \mathrm{Xe}$ ions causes larger variations compared with the virgin sample than irradiation with $74 \mathrm{MeV} \mathrm{Kr}$ ions.

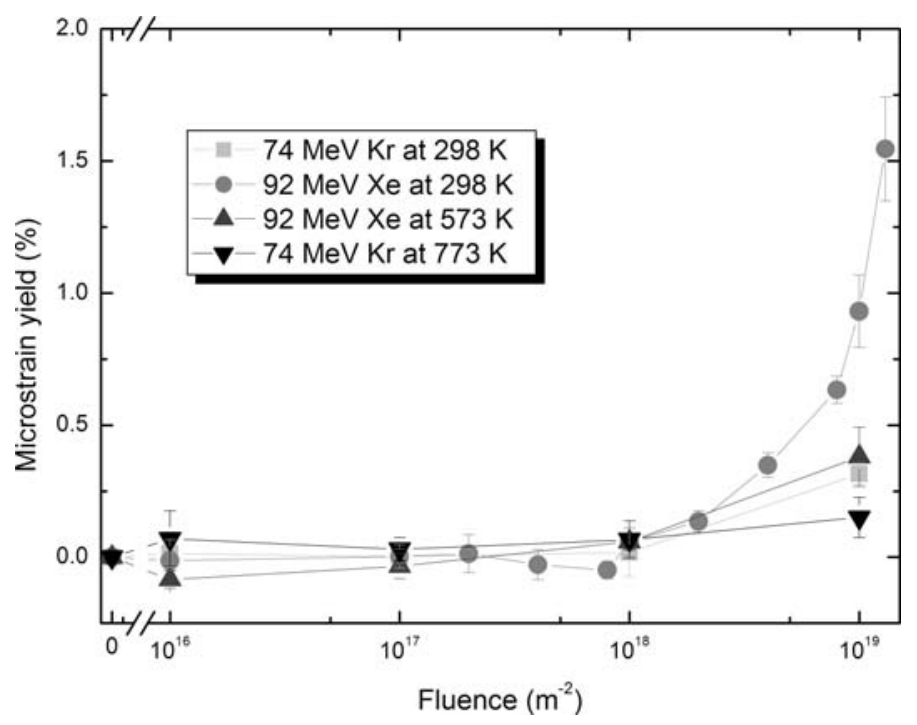

Figure 5: Variation of the microstrain yield as a function of ion fluence for irradiations carried out on IRRSUD.

The effect of temperature is still beneficial concerning the irradiation damage because the higher the temperature, the lower the microstrains in the $\mathrm{Ti}_{3} \mathrm{SiC}_{2}$ crystal (Figure 5).

These results can be completed by two other observations. First, given that the observations by X-TEM did not reveal deformation fields in the crystal, and that no variation of lattice parameters was measured by LI-XRD, it seems 
reasonable that no broadening has been observed for specimens irradiated with $930 \mathrm{MeV} \mathrm{Xe}$ ions. Second, some broadening measurements carried out on the (008) peak have led to both trends and values similar to those presented for the (104) peak: thus, variations of the microstrain yield induced by irradiation appear as isotropic.

\section{Discussion}

The first important result arising from this study is that titanium silicon carbide is not very sensitive to electronic excitation. In other word, if an electronic stopping power threshold for the formation of latent tracks in this material exists, it would be greater than $28 \mathrm{keV} \mathrm{nm}^{-1}$. This result is not proper to $\mathrm{Ti}_{3} \mathrm{SiC}_{2}$ since most of metals [46,47], but also some ceramics such as $\mathrm{SiC}$ [48-50] or $\mathrm{TiC}$ and $\mathrm{TiSi}_{2}$ (secondary phases present in the samples, which do not seem to be affected by electronic interactions either) require huge electronic energy loss to be damaged by such interactions.

On the contrary, nuclear shocks create many defects and cause the loss of the nanolamellar structure of $\mathrm{Ti}_{3} \mathrm{SiC}_{2}$, albeit without leading to amorphization like in the case of $\mathrm{SiC}$ for doses reaching some tenths of dpa [51-57]. It was shown that defect creation reduces dislocation mobility, and increases hardness [58]. Similarly, the nanolamellar structure confers some plasticity to $\mathrm{Ti}_{3} \mathrm{SiC}_{2}[17,24,59,60]$, and consequently the nuclear shocks could embrittle this material. Liu et al. studied the variation of hardness by nano-indentation of aluminum-doped $\mathrm{Ti}_{3} \mathrm{SiC}_{2}$ samples after irradiation with both $74 \mathrm{MeV} \mathrm{Kr}$ and $92 \mathrm{MeV}$ Xe ions [35,36]; the substitution of silicon atoms by aluminum would be an effective way to eliminate $\mathrm{TiC}$ while increasing the resistance to oxidation of $\mathrm{Ti}_{3} \mathrm{SiC}_{2}$, and without changing its mechanical properties [61-63]. In these studies, they have actually shown an increase in hardness with ion fluence, as well as a decrease of the irradiation effect when the temperature increases. Moreover, for the highest fluences reached at room temperature ( $10^{19}$ and $2 \times 10^{19} \mathrm{~m}^{-2}$ for $74 \mathrm{MeV} \mathrm{Kr}$ and $92 \mathrm{MeV}$ Xe respectively), they have not noted any cracking at the indentation corners, indicating that $\mathrm{Ti}_{3} \mathrm{SiC}_{2}$ still retains some plasticity. However, the dpa generated by this irradiation at the surface ( $<1 \mathrm{dpa}$, see Figure 1 ) are low compared with the dose required to cause the loss of the nanolamellar structure (Figure 3).

Contrary to what had been assumed previously [30], the evolution of lattice parameters appears to be due to nuclear shocks: first there is no change for irradiations with $930 \mathrm{MeV}$ Xe ions, and second there is some strong variation for those with $4 \mathrm{MeV}$ Au ions. To verify this hypothesis, we plotted the evolution of lattice parameters as a function of dpa for irradiations performed at room temperature (Figure 6). We have also added the values obtained for samples irradiated with $930 \mathrm{MeV}$ Xe ions, and those for the sample irradiated at $298 \mathrm{~K}$ with $4 \mathrm{MeV}$ Au ions to $10^{17} \mathrm{~m}^{-2}$ ( $0,038 \mathrm{dpa})$; for the latter one, the estimation of the a parameter is tarnished by a significant error due to the superposition of diffractograms of both virgin and irradiated areas.

After fitting the experimental data with arbitrary functions (linear for the a parameter and power of exponent between 0 and 1 for the c parameter, see Figure 6), it appears that changes in lattice parameters are directly attributable to nuclear shocks. The evolution of the unit cell volume (obtained from the functions determined for a and c) shows a maximum, as noted on the plot of the unit cell volume for irradiation with $92 \mathrm{MeV}$ Xe ions at $298 \mathrm{~K}$ (Figure 4). Hence, it seems that there is a critical dose beyond which the volume of the unit cell decreases. This critical dose is estimated to be $\sim 0.1$ dpa: it corresponds to a fluence of $6.3 \times 10^{18} \mathrm{~m}^{-2}$ for $92 \mathrm{MeV}$ Xe ions, a result in accordance with Figure 4 . Concerning the irradiations with $74 \mathrm{MeV} \mathrm{Kr}$ ions, the critical dose corresponds to a fluence of $1.2 \times 10^{19} \mathrm{~m}^{-2}$, so that the maximum was not reached for this irradiation (fluence up to $10^{19} \mathrm{~m}^{-2}$ ). Eventually, according to the results obtained as a function of temperature (see variations of the unit cell volume in Figure 4), it seems that the critical dose increases with increasing temperature.

Results also show that nuclear shocks, certainly through the changes in lattice parameters, increase microstrains in $\mathrm{Ti}_{3} \mathrm{SiC}_{2}$. To obtain this conclusion, we assumed that the peak broadening is only due to microstrains, so that the crystallite size is large enough not to induce peak broadening. Liu et al. have also conducted such measurements on their materials $\left(\mathrm{Ti}_{3} \mathrm{Si}_{0,90} \mathrm{Al}_{0,10} \mathrm{C}_{2}\right)$ after Rietveld refinement [34]. Thus, they have shown an increase of the microstrain yield, of the same order of magnitude for the same irradiations at the same temperatures; this result supports our hypothesis concerning the origin of the peak broadening. 

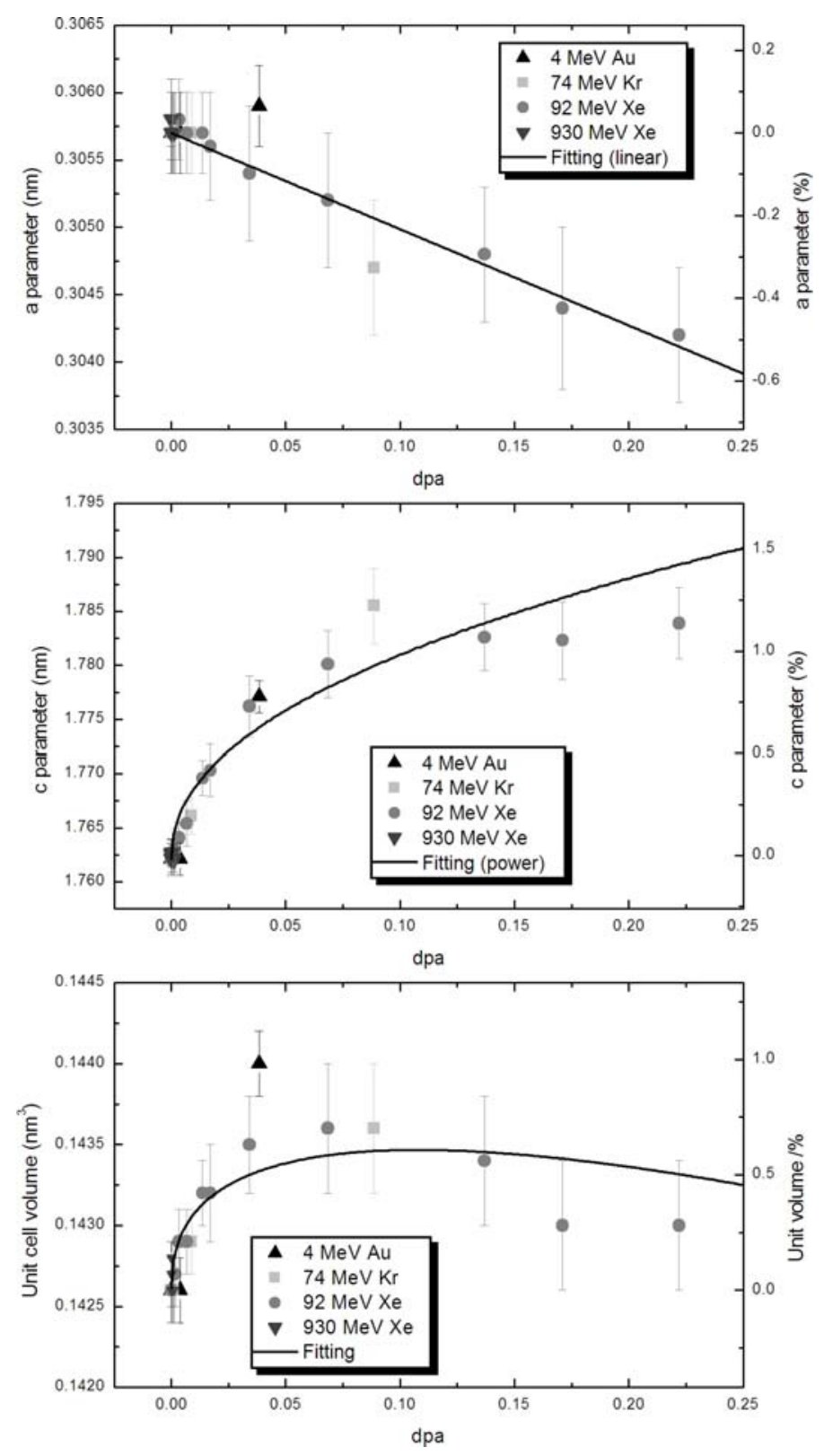

Figure 6: Change in lattice parameters as a function of the number of displacements per atom for irradiations performed at $298 \mathrm{~K}$; the fitting curve of the unit cell volume data was obtained from those of a and c parameters.

The irradiations performed at high temperatures show a decrease in damage caused by nuclear shocks. Indeed, the creation of irradiation defects being an athermal phenomenon, an increase of the irradiation temperature increases the diffusion of species constituting a material. Therefore, the probability of recombination of Frenkel pairs (the main defect induced by nuclear shocks) increases with temperature, thereby reducing the effect of nuclear shocks. This result leads to the almost complete lack of damage in the sample irradiated at $1223 \mathrm{~K}$, compared with the virgin sample, allowing $\mathrm{Ti}_{3} \mathrm{SiC}_{2}$ to be considered as a promising material for use as fuel cladding in the GFR.

Finally, by comparing this work with the one of Liu et al. [34], two results appear to be different. First, they noted for the high fluences, in both $74 \mathrm{MeV} \mathrm{Kr}$ and $92 \mathrm{MeV} \mathrm{Xe}$, a difference in the relative intensities, and especially the intensity of the (102) peak that becomes larger than that of (101). This change, which is not noticeable in our diffraction patterns, would be due to the formation of $\beta-\mathrm{Ti}_{3} \mathrm{SiC}_{2}$ clusters in the irradiated area. Second, they did not report any change concerning the a parameter, regardless of the fluence. The origin of these discrepancies remains to be determined. However, possible explanations would be that either the materials studied are different (for instance concerning the effect of aluminum doping), or the techniques for both acquiring and processing diffraction data are not totally similar. 


\section{Conclusion}

This work was devoted to the study of the structural behavior of $\mathrm{Ti}_{3} \mathrm{SiC}_{2}$ under irradiation. We first showed that this material is not sensitive to electronic interactions below $28 \mathrm{keV} \mathrm{nm}^{-1}$. On the contrary, nuclear interactions greatly damage the structure of $\mathrm{Ti}_{3} \mathrm{SiC}_{2}$ without leading to amorphization. Ballistic collisions create defects that cause hardening of the material, and induce the loss of its nanolamellar structure that probably increase its brittleness. We also showed that nuclear interactions are the source of anisotropic changes in lattice parameters (expansion along c and contraction along a), which cause an increase of the unit cell volume up to a critical dose estimated at $0.1 \mathrm{dpa}$ for irradiation performed at $298 \mathrm{~K}$, and an increase of the microstrains in the crystal. An increase of the temperature of irradiation induce a significant decrease of the damage induced by nuclear interactions: $\mathrm{Ti}_{3} \mathrm{SiC}_{2}$ hence seems promising as an element of the GFR core component.

\section{Acknowledgements}

The authors would like to greatly thank Olivier Valfort of the SPIN center of the École Nationale Supérieure des Mines (Saint-Étienne, France) for his help during low incidence X-ray diffraction analyzes. They acknowledge financial supports from both the French CNRS and CEA METSA network, and the French research group MATINEX.

\section{References}

[1] US.DoE, <http://nuclear.energy.gov/genIV/neGenIV1.html>.

[2] G.W. Hollenberg, C.H. Henager, G.E. Youngblood, D.J. Trimble, S.A. Simonson, G.A. Newsome, E. Lewis, The effect of irradiation on the stability and properties of monolithic silicon carbide and SiCf/SiC composites up to 25 dpa, J. Nucl. Mater. 219 (1995) 70-86.

[3] L.L. Snead, S.J. Zinkle, J.C. Hay, M.C. Osborne, Amorphization of SiC under ion and neutron irradiation, Nucl. Instrum. Methods Phys. Res. Sect. B: Beam Interact. Mater. Atoms 141 (1998) 123-132.

[4] T. Yano, H. Miyazaki, M. Akiyoshi, T. Iseki, X-ray diffractometry and high-resolution electron microscopy of neutron-irradiated SiC to a fluence of 1.9×1027 n/m2, J. Nucl. Mater. 253 (1998) 78-86.

[5] Y. Katoh, H. Kishimoto, A. Kohyama, The influences of irradiation temperature and helium production on the dimensional stability of silicon carbide, J. Nucl. Mater. 307-311 (2002) 1221-1226.

[6] L.L. Snead, T. Nozawa, Y. Katoh, T.S. Byun, S. Kondo, D.A. Petti, Handbook of SiC properties for fuel performance modeling, J. Nucl. Mater. 371 (2007) 329-377.

[7] K. H Park, T. Hinoki, A. Kohyama, Influence of irradiation-induced defects on fracture behavior in highly pure SiC, J. Nucl. Mater. 367 (2007) 703-707.

[8] J.J. Nickl, K.K. Schweitzer, P. Luxenberg, Gasphasenabscheidung im Systeme Ti-C-Si, J. Less-Common Metals 26 (1972) 335-353.

[9] R. Pampuch, J. Lis, L. Stobierski, M. Tymkiewicz, Solid Combustion Synthesis of Ti3SiC2, J. Eur. Ceram. Soc. 5 (1989) 283-287.

[10] R. Pampuch, J. Lis, J. Piekarczyk, L. Stobierski, Ti3SiC2-based materials produced by self-propagating high temperature synthesis and ceramic processing, J. Mater. Synth. Process. 1 (1993) 93-100.

[11] J. Lis, R. Pampuch, L. Stobierski, Reactions during SHS in a Ti-Si-C system, Int. J. Self-Propag. High-Temp. Synth. 1 (1992) 401.

[12] J. Lis, R. Pampuch, J. Piekarczyk, L. Stobierski, New ceramics based on Ti3SiC2, Ceram. Int. 19 (1993) 219-

222.

[13] J. Lis, Y. Miyamoto, R. Pampuch, K. Tanihata, Ti3SiC2-based materials prepared by HIP-SHS techniques, Mater. Lett. 22 (1995) 163-168.

[14] T. Goto, T. Hirai, Chemically vapor-deposited Ti3SiC2, Mater. Res. Bull. 22 (1987) 1195-1201.

[15] M.W. Barsoum, T. El-Raghy, Synthesis and characterization of a remarkable ceramic: Ti3SiC2, J. Am. Ceram. Soc. 79 (1996) 1953-1956.

[16] M.W. Barsoum, The M(n+1)AX(n) phases: A new class of solids; Thermodynamically stable nanolaminates, Prog. Solid State Chem. 28 (2000) 201-281.

[17] C.J. Gilbert, D.R. Bloyer, M.W. Barsoum, T. El-Raghy, A.P. Tomsia, R.O. Ritchie, Fatigue-crack growth and fracture properties of coarse and fine-grained Ti3SiC2, Scr. Mater. 42 (2000) 761-767.

[18] M.W. Barsoum, T. El-Raghy, C.J. Rawn, W.D. Porter, H. Wang, E.A. Payzant, C.R. Hubbard, Thermal properties of Ti3SiC2, J. Phys. Chem. Solids 60 (1999) 429-439.

[19] E.H. Kisi, J.A.A. Crossley, S. Myhra, M.W. Barsoum, Structure and crystal chemistry of Ti3SiC2, J. Phys. Chem. Solids 59 (1998) 1437-1443.

[20] N.F. Gao, Y. Miyamoto, D. Zhang, On physical and thermochemical properties of high-purity Ti3SiC2, Mater. Lett. 55 (2002) 61-66.

[21] T. El-Raghy, M.W. Barsoum, A. Zavaliangos, S.R. Kalidindi, Processing and mechanical properties of Ti3SiC2: II, effect of grain size and deformation temperature, J. Am. Ceram. Soc. 82 (1999) 2855-2860. 
[22] M.W. Barsoum, T. El-Raghy, The MAX phases: Unique new carbide and nitride materials - Ternary ceramics turn out to be surprisingly soft and machinable, yet also heat-tolerant, strong and lightweight, Am. Scientist 89 (2001) 334-343.

[23] M.W. Barsoum, L. Farber, T. El-Raghy, Dislocations, kink bands, and room-temperature plasticity of Ti3SiC2, Metall. Mater. Trans. A 30 (1999) 1727-1738.

[24] B.J. Kooi, R.J. Poppen, N.J.M. Carvalho, J.Th.M. De Hosson, M.W. Barsoum, Ti3SiC2: A damage tolerant ceramic studied with nano-indentations and transmission electron microscopy, Acta Mater. 51 (2003) 2859-2872.

[25] M.W. Barsoum, T. El-Raghy, L. Ogbuji, Oxidation of Ti3SiC2 in air, J. Electrochem. Soc. 144 (1997) 2508-

2516.

[26] M. Radovic, M.W. Barsoum, T. El-Raghy, J. Seidensticker, S. Wiederhorn, Tensile properties of Ti3SiC2 in the 25-1300 degrees C temperature range, Acta Mater. 48 (2000) 453-459.

[27] J. Travaglini, M.W. Barsoum, V.D. Jovic, T. El-Raghy, The corrosion behavior of Ti3SiC2 in common acids and dilute $\mathrm{NaOH}$, Corros. Sci. 45 (2003) 1313-1327.

[28] V.D. Jovic, B.M. Jovic, S. Gupta, T. El-Raghy, M.W. Barsoum, Corrosion behavior of select MAX phases in $\mathrm{NaOH}, \mathrm{HCl}$ and H2SO4, Corros. Sci. 48 (2006) 4274-4282.

[29] J.C. Nappé, C. Maurice, Ph. Grosseau, F. Audubert, B. Guilhot, M. Beauvy, L. Thomé, M. Benabdesselam, Microstructural changes induced by low energy heavy ion irradiation in titanium silicon carbide, Under Review in Journal of the European Ceramic Society.

[30] J.C. Nappé, Ph. Grosseau, F. Audubert, B. Guilhot, M. Beauvy, M. Benabdesselam, I. Monnet, Damages induced by heavy ions in titanium silicon carbide: Effects of nuclear and electronic interactions at room temperature, J. Nucl. Mater. 385 (2009) 304-307.

[31] J.C. Nappé, Ph. Grosseau, B. Guilhot, F. Audubert, M. Beauvy, M. Benabdesselam, Heavy ions induced damages in Ti3SiC2: Effect of irradiation temperature, Mechanical Properties and Performance of Engineering Ceramics and Composites IV, 30, Hoboken, NJ, USA, D. Singh \& W.M. Kriven (2010) 199-204.

[32] J.C. Nappé, I. Monnet, Ph. Grosseau, F. Audubert, B. Guilhot, M. Beauvy, M. Benabdesselam, Hill formation on titanium silicon carbide surface irradiated with swift heavy ions, Under Review.

[33] M. Le Flem, X. Liu, S. Doriot, T. Cozzika, I. Monnet, Irradiation damage in Ti3(Si,Al)C2: a TEM investigation, Int. J. Appl. Ceram. Technol. 7 (2010) 766-775.

[34] X. Liu, M. Le Flem, J.L. Béchade, F. Onimus, T. Cozzika, I. Monnet, XRD investigation of ion irradiated Ti3Si0.90Al0.10C2, Nucl. Instrum. Methods Phys. Res. Sect. B: Beam Interact. Mater. Atoms 268 (2010) 506-512. [35] M. Le Flem, X. Liu, S. Doriot, T. Cozzika, F. Onimus, J.L. Bechade, I. Monnet, Y. Zhou, Ti3(Si,Al)C2 for nuclear application: Investigation of irradiation effects induced by charged particles, Mechanical Properties and Performance of Engineering Ceramics and Composites IV, 30, Hoboken, NJ, USA, D. Singh \& W.M. Kriven (2010) 189-198.

[36] X. Liu, M. Le Flem, J.L. Béchade, I. Monnet, Nanoindentation investigation of heavy ion irradiated Ti3(Si,Al)C2, J. Nucl. Mater. 401 (2010) 149-153.

[37] J.F. Ziegler, <http://www.srim.org/>.

[38] M. Beauvy, C. Dalmasso, C. Thiriet-Dodane, D. Simeone, D. Gosset, Damages in ceramics for nuclear waste transmutation by irradiation with swift heavy ions, Nucl. Instrum. Methods Phys. Res. Sect. B: Beam Interact. Mater. Atoms 242 (2006) 557-561.

[39] G. Sattonnay, S. Moll, L. Thomé, C. Legros, M. Herbst-Ghysel, F. Garrido, J.-M. Costantini, C. Trautmann, Heavy-ion irradiation of pyrochlore oxides: Comparison between low and high energy regimes, Nucl. Instrum. Methods Phys. Res. Sect. B: Beam Interact. Mater. Atoms 266 (2008) 3043-3047.

[40] A. Quentin, I. Monnet, D. Gosset, B. Lefrançois, S. Bouffard, Amorphisation of ZnAl2O4 spinel under heavy ion irradiation, Nucl. Instrum. Methods Phys. Res. Sect. B: Beam Interact. Mater. Atoms 267 (2009) 980-982.

[41] M. Brunel, F. de Bergevin, Diffraction d'un faisceau de rayons X en incidence très rasante, Acta Crystallogr. Sect. A: Found. Crystallogr. 42 (1986) 299-303.

[42] B. Agius, M. Froment, F. Abel, L. Beaunier, G. Blaise, L. Bosio, G. Hollinger, A. Huber, A. Hugot-Le Goff, J. Klein, P. Pertosa, L. Porte, Surfaces, interfaces et films minces: Observation et analyse, Paris, Dunod Bordas (1990).

[43] M. Brunel, Rayons X rasants et surfaces, J. Phys. IV 6 (1996) C4-321-340.

[44] W. Jeitschko, H. Nowotny, Die Kristallstruktur von Ti3SiC2 - ein neuer Komplexcarbid-Typ, Monatsh. Chem. 98 (1967) 329-337.

[45] M.W. Barsoum, T. El-Raghy, A progress report on Ti3SiC2, Ti3GeC2, and the H-phases, M2BX, J. Mater. Synth. Process. 5 (1997) 197-216.

[46] A. Dunlop, P. Legrand, D. Lesueur, N. Lorenzelli, J. Morillo, A. Barbu, S. Bouffard, Phonon soft modes and damage production by high electronic excitations in pure metals, Europhys. Lett. 15 (1991) 765-770.

[47] P. M. Ossi, R. Pastorelli, Structural changes induced by fast heavy ion irradiation of pure metals, Nucl. Instrum. Methods Phys. Res. Sect. B: Beam Interact. Mater. Atoms 122 (1997) 566-570.

[48] A. Benyagoub, A. Audren, L. Thome, F. Garrido, Athermal crystallization induced by electronic excitations in ion-irradiated silicon carbide, Appl. Phys. Lett. 89 (2006) 241914.

[49] A. Audren, I. Monnet, D. Gosset, Y. Leconte, X. Portier, L. Thomé, F. Garrido, A. Benyagoub, M. Levalois, N. Herlin-Boime, C. Reynaud, Effects of electronic and nuclear interactions in SiC, Nucl. Instrum. Methods Phys. Res. Sect. B: Beam Interact. Mater. Atoms 267 (2009) 976-979. 
[50] S. Intarasiri, L.D. Yu, S. Singkarat, A. Hallen, J. Lu, M. Ottosson, J. Jensen, G. Possnert, Effects of low-fluence swift iodine ion bombardment on the crystallization of ion-beam-synthesized silicon carbide, J. Appl. Phys. 101 (2007) 084311.

[51] R.R. Hart, H.L. Dunlap, O.J. Marsh, Disorder produced in SiC by ion bombardment, Radiat. Eff. Defects Solids 9 (1971) 261-266.

[52] J.A. Edmond, R.F. Davis, S.P. Withrow, K.L. More, Ion-implantation in beta-SiC - Effect of channeling direction and critical energy for amorphization, J. Mater. Res. 3 (1988) 321-328.

[53] C.W. White, C.J. McHargue, P.S. Sklad, L.A. Boatner, G.C. Farlow, Ion implantation and annealing of crystalline oxides, Mater. Sci. Rep. 4 (1989) 41-146.

[54] J.M. Williams, C.J. McHargue, B.R. Appleton, Structural alterations in SiC as a result of $\mathrm{Cr}+$ and $\mathrm{N}+$ implantation, Nucl. Instrum. Methods Phys. Res. 209-210 (1983) 317-323.

[55] J.A. Spitznagel, S. Wood, W.J. Choyke, N.J. Doyle, J. Bradshaw, S.G. Fishman, Ion beam modification of 6H/15R SiC crystals, Nucl. Instrum. Methods Phys. Res. Sect. B: Beam Interact. Mater. Atoms 16 (1986) $237-243$.

[56] N.G. Chechenin, K.K. Bourdelle, A.V. Suvorov, A.X. Kastilio-Vitloch, Damage and aluminum distributions in SiC during ion implantation and annealing, Nucl. Instrum. Methods Phys. Res. Sect. B: Beam Interact. Mater. Atoms 65 (1992) 341-344.

[57] L.L. Horton, J. Bentley, L. Romana, A. Perez, C.J. McHargue, J.C. McCallum, Microstructural characterization of iron ion implantation of silicon carbide, Nucl. Instrum. Methods Phys. Res. Sect. B: Beam Interact. Mater. Atoms 65 (1992) 345-351.

[58] W. Bolse, S.D. Peteves, Modification of the mechanical-properties of ceramic surfaces by energetic ion irradiation, Nucl. Instrum. Methods Phys. Res. Sect. B: Beam Interact. Mater. Atoms 68 (1992) 331-341.

[59] M.W. Barsoum, T. El-Raghy, Room-temperature ductile carbides, Metall. Mater. Trans. A 30 (1999) $363-369$.

[60] M.W. Barsoum, T. Zhen, S.R. Kalidindi, M. Radovic, A. Murugaiah, Fully reversible, dislocation-based compressive deformation of Ti3SiC2 to 1GPa, Nat. Mater. 2 (2003) 107-111.

[61] J.Y. Wang, Y.C. Zhou, First-principles study of equilibrium properties and electronic structure of Ti3Si0.75Al0.25C2 solid solution, J. Phys.: Condens. Matter 15 (2003) 5959-5968.

[62] H.B. Zhang, Y.C. Zhou, Y.W. Bao, M.S. Li, Improving the oxidation resistance of Ti3SiC2 by forming a Ti3Si0.9Al0.1C2 solid solution, Acta Mater. 52 (2004) 3631-3637.

[63] Y.C. Zhou, H.B. Zhang, M.Y. Liu, J.Y. Wang, Y.W. Bao, Preparation of TiC free Ti3SiC2 with improved oxidation resistance by substitution of Si with Al, Mater. Res. Innovations 8 (2004) 97-102 